review of the initiative was performed over a one-year period from November 2019 to 2020. Feedback was collected regarding student confidence pre- and post-research project.

Results Twenty-three projects were undertaken by 28 healthcare students from both Cardiff and Swansea Universities alongside 15 clinical supervisors working in paediatrics in South Wales. Seven projects have been completed so far, with two students dropping out due alternative to University commitments. Success stories include one publication in Archives of Diseases in Childhood, a further currently under peer review, three national presentations, one paediatric podcast and six medical education resources for use in local university health boards. $100 \%$ of students reported they were enthusiastic towards paediatric research and were excited by the opportunity to be involved. After completing a project, $50 \%$ felt more confident with research techniques and 38\% felt confident at project initiation. $100 \%$ agreed that they had more awareness of how to undertake research alongside their future clinical careers.

Conclusions Undergraduate students typically have a high level of enthusiasm to be involved and gain experience within research but report it can often be difficult to know how. This simple initiative has supported multidisciplinary healthcare students to gain confidence, awareness and practical experience in child health research and quality improvement. Although the pandemic has interrupted both project proposals and completion significantly, WORLD CUPS has been a success and may provide a framework for future undergraduate research initiatives.

\section{FAMILY PRESENCE ON THE HDU WARD ROUND: BALANCING COMPASSIONATE CARE WITH PATIENT PRIVACY AND CONFIDENTIALITY}

Ben Hughes, Peter Lillitos, Shuba Barwick. UK

\subsection{6/bmjpo-2021-RCPCH.27}

Background The paediatric cardiology HDU ward can be a busy environment with complex and often very unwell children. Ward rounds are imperative for information sharing and complex decision-making, but have traditionally been run without parental presence to maintain patient confidentiality. Parents were asked to leave their children creating problems twofold; both child and parent would be distressed at not being with the other when the child is often critically unwell, and parents would have to track down doctors for clinical updates and management plans. We proposed the use of noise-cancelling headphones for use during the ward round to maintain confidentiality, whilst keeping parents by their child's bedside.

Objectives

1. To understand and evaluate the current HDU parental experience.

2. To implement a strategy to improve the HDU experience.

3. To evaluate the change.

Methods Two questionnaires were constructed to collect retrospective and prospective data. Telephone discussions with parents of children who were admitted during July-August 2019 took place to answer the questionnaire before the implementation of headphones. Anonymised paper questionnaires were given to parents of children admitted during
September-October 2019, when headphones were being used. Headphones were given to all parents present in HDU to be worn at all times, apart from when their child was being reviewed so they could contribute. Doctors and nurses on the cardiology ward were also given a questionnaire for their opinions about how headphones have altered working practice.

Results Prior to implementation, all parents were asked to leave ward round at some point during admission (100\%, $\mathrm{n}=7$ ). After headphone implementation, $90 \%$ of parents were invited to stay $(n=12)$. Parents were most thankful for the support they were able to provide for their child constantly during ward round, and the ease at which they were able to gather information from the medical team about their childs' progress so far and subsequent plans. Staff results mirrored parental responses, indicating enhanced confidentiality and parental inclusion in ward round discussions were key positive factors following implementation.

Conclusions Implementing headphones enabled parents to engage with ward rounds. In a busy environment with complex and unwell children, we should do our utmost to reduce patient and parental anxiety, and help empower parents in challenging times. This holistic approach is imperative to a positive patient journey and good rounded compassionate care.

\section{USING THE COVID-19 PANDEMIC AS A LEARNING TOOL TO SHAPE PAEDIATRIC OUTPATIENT CONSULTATIONS}

Rosanne Verow, Rachel Cotton, Serena Braccio, Andrea Goddard. United Kingdom

\subsection{6/bmjpo-2021-RCPCH.28}

Background The declaration of a nationwide COVID-19 lockdown resulted in rapid adaptations to the NHS, including Paediatric Outpatient Consultations. At short notice, many Trusts converted consultations in General Paediatric outpatients from traditional face-to-face to telephone consultations. General Practitioners have been using this method of assessment, with the backing of the British Medical Association, as a safe and acceptable practice for many years.

Objectives We set out to perform a retrospective review of the lessons learned from Paediatric outpatient telephone consultations during COVID-19 and how these can be applied to improve the outpatient clinical pathway. Our aims and objectives evaluated:

1. The proportion of patients successfully contacted by telephone.

2. The proportion of presenting complaints which had resolved by the time of the appointment.

3. The proportion of patients who could be discharged from the General Paediatric clinic through telephone consultation.

4. The number of patients who we arranged to see in a face-toface appointment within a few weeks (as deemed necessary by the phoning clinician).

5. The number of patients who needed further investigations.

Methods Two registrars (ST6+) and one senior house officer (ST2), with guidance from a dedicated General Paediatric Consultant, was assigned to conduct telephone consultations for all new patients booked into General Paediatric clinics between the $24 / 03 / 2020$ to $31 / 05 / 2020$. Most patients had 
been referred and appointments booked pre-COVID but urgent (2 -week) referrals from GPs were also seen.

Patients/parents/carers were called at least 3 times on 3 different occasions over at least 2 days. If they did not answer they were listed as 'was not brought'. Calls were made between 9 am to $5 \mathrm{pm}$ Monday to Friday.

Results 262 new patients had new General Paediatric Clinic appointments and 235 (90\%) were successfully contacted. 27 (10\%) of patients 'were not brought'. These 27 patients were excluded from on-going analysis.

Following one telephone consultation, 105 (45\%) contacted patients could be discharged from the General Paediatric clinic with parental agreement. Of these 27 (11\%) patients had a complaint which had resolved by the time of the appointment and $19(8 \%)$ patients had already been seen by a private consultant or other NHS consultant. Thus 46 (20\%) of the contacted patients did not need their General Paediatric appointment.

Only 7 (3\%) patients needed urgent face-to face-review of which 4 were urgent 2-week wait referrals by the GP. 155 (66\%) patients needed no investigations.

Conclusions The NHS is going through unchartered, challenging time. However, this provides opportunities to adapt and evolve services, improving efficiency of care for both the families we look after and health service staff. The data above highlights that almost half of the new General Paediatric outpatients could be successfully discharged from clinic after one telephone consultation. During a time of significant anxiety and uncertainty families avoided hospital contact. A similar system when we return to normality could lead to fewer absences from school and less time off work for parents. Out experience suggests that initial telephone consultations with new General Paediatric patients may be an efficient way to make first patient contact.

\section{CLINICAL CORRELATES OF CORD ARTERIAL LACTATE IN TERM BABIES}

Pei Sen Tee. UK

\subsection{6/bmjpo-2021-RCPCH.29}

Background Umbilical cord blood gas analysis is recommended to be taken when there has been concern about the baby in labour or immediately following birth and cord arterial lactate (CAL) has become a standard measurement on blood gas reports. However, evidence regarding thresholds for concern or appropriate management remains limited. Within our unit, guidance on further management of infants following detection of potentially 'raised' CAL was ratified based on available literature.

Objectives This study reports on the clinical correlates of a raised cord arterial lactate following introduction of a guidance to manage newborns with raised CAL.

Methods A single-centre retrospective review of all term neonates (>35 weeks gestational age) with a recorded CAL over a 6-month period (July 2018 to December 2018). Babies were identified from maternity monthly statistics and data extracted from electronic medical records. Clinical course and adverse events were evaluated between risk groups: Low-risk CAL $\leq 5$ $\mathrm{mmol} / \mathrm{L}$, moderate-risk CAL 5-10 $\mathrm{mmol} / \mathrm{L}$ and high-risk CAL $\geq 10 \mathrm{mmol} / \mathrm{L}$. Adverse events include therapeutic hypothermia,

\begin{tabular}{|c|c|c|}
\hline $\begin{array}{l}\text { CAL } \\
\text { (mmol/L) }\end{array}$ & Immediate Action & $\begin{array}{l}\text { Further management/ } \\
\text { investigations }\end{array}$ \\
\hline$<5$ & $\begin{array}{l}\text { Baby to stay with mother. } \\
\text { 'Routine' postnatal care }\end{array}$ & No follow-up \\
\hline $5-10$ & $\begin{array}{l}\text { Baby to stay with mother, keep } \\
\text { warm, encourage early breastfeeding. }\end{array}$ & $\begin{array}{l}\text { - 4-hourly observations on postnatal } \\
\text { ward for } 24 \text { hours. } \\
\text { - Consider repeat blood gas in 4-6 } \\
\text { hours from well perfused heel }\end{array}$ \\
\hline$>10$ & $\begin{array}{l}\text { Consider admission to unit, cerebral } \\
\text { function monitoring and careful } \\
\text { neurological assessment }\end{array}$ & $\begin{array}{l}\text { - Close observation including regular } \\
\text { blood gases and blood glucose } \\
\text { monitoring. } \\
\text { - Discussion with senior clinician } \\
\text { regarding plans (feeding). }\end{array}$ \\
\hline
\end{tabular}

mechanical ventilation, neonatal death and usage of non-invasive ventilation.

Results Among 2591 infants born $\geq 35$ weeks gestation, 658 (25\%) had a recorded CAL $(44 \%$ had a CAL $<5 \mathrm{mmol} / \mathrm{L}$, $49 \%$ had CAL $5-10 \mathrm{mmol} / \mathrm{L}$ and $7 \%$ had CAL $\geq 10 \mathrm{mmol} / \mathrm{L}$ ). Gender gestation and birth weight were in equal proportions in all 3 groups. The high-risk group with $\mathrm{CAL} \geq 10 \mathrm{mmol} / \mathrm{L}$ required more resuscitation at birth, NICU admission and had more adverse events compared to groups with $\mathrm{CAL} \leq 10$ $\mathrm{mmol} / \mathrm{L}$. There was no difference in these events in infants where $\mathrm{CAL}<5 \mathrm{mmol} / \mathrm{L}$ compared to those with a CAL 5-10 $\mathrm{mmol} / \mathrm{L}$.

A repeat blood lactate level was taken in $48 \%$ and $98 \%$ of CAL $5-10 \mathrm{mmol} / \mathrm{L}$ and $\mathrm{CAL} \geq 10 \mathrm{mmol} / \mathrm{L}$ groups respectively. The time range for first repeat varied widely and babies who had increased lactate level after repeat did not receive more treatment than those where the lactate fell. Routine repeat of blood lactate levels in clinically well babies with CAL 5-10 $\mathrm{mmol} / \mathrm{L}$ did not appear to change management.

Conclusions A large number of babies are currently labelled as moderate to high risk based on a single raised CAL which may lead to unnecessary medical interventions. Better evidence is needed to determine the significance of a raised CAL, define clinically important thresholds for concern and optimal interventional strategies.

\section{MEDICATION ERRORS IN PAEDIATRICS DEPARTMENT AND THEIR IMPACT ON PATIENT SAFETY}

Pei Sen Tee. UK

\subsection{6/bmjpo-2021-RCPCH.30}

Background Medication errors (MEs) represent a significant burden to healthcare system and the frequency of potentially harmful MEs was found to be three times higher in paediatric population when compared to adults ${ }^{1}$.

Objectives This review aims to analyse MEs to improve medication safety and compare the frequency of MEs compared to the previous audit cycle.

Methods This is a retrospective analysis of medication errors in paediatric ward and neonatal unit utilising critical incident reporting forms (Datix) that were submitted from October 2018 to September 2019. These reports were obtained 